\title{
TO SUPPORT IOT COLLABORATIVE EXPRESSIVENESS ON THE SHOP FLOOR
}

\author{
Aranda Muñoz, Álvaro (1,2); \\ Eriksson, Yvonne (1); \\ Yamamoto, Yuji (1); \\ Florin, Ulrika (1); \\ Sandström, Kristian (2) \\ 1: Mälardalen University; \\ 2: RISE
}

\begin{abstract}
The availability of new research for IoT support and the human-centric perspective of industry 4.0 opens a gap to support operators in unleashing their creativity so they can provide improvements opportunities with IoT technology. This paper presents a case-study carried out in four Swedish manufacturing companies, where four different workshops were facilitated to support operators in the conceptualization of manufacturing improvements with IoT technologies. The empirical material gathered during these workshops has been analyzed in five different reflective sessions and discussed in light of previous research from industry 4.0, operators, and IoT support. Results indicate that operators can collaboratively create conceptual IoT solutions and that expressiveness in communicating their ideas and needs using IoT technology is more relevant than technical aspects and details of their proposed IoT solutions. This technological expressiveness is identified as a necessary skill to be cultivated on the shop floor and can potentially contribute to making a more effective and socially sustainable industrial landscape in the future.
\end{abstract}

Keywords: Case study, Collaborative design, Early design phases, Internet of Things

\section{Contact:}

Aranda Muñoz, Álvaro

Mälardalen University

Information Design

Sweden

alvaro.aranda.munoz@ri.se 


\section{INTRODUCTION}

The concept of Industry 4.0 promises a new paradigm of smart manufacturing through the introduction of technologies such as the Internet of Things (IoT). This introduction of novel technologies into manufacturing contexts will influence operators (Romero et al., 2020), as working in these novel settings can demand a re-skilling of human capital (Gorecky et al., 2014; Pinzone et al., 2017) and necessitate that operators participate in activities that require creative, strategic and problem-solving skills (Wichmann et al., 2019).

In this respect, we see an opportunity to engage operators in creative thinking with technologies such as IoT to solve challenges and capitalise on the opportunities they see on a regular basis. However, operators lack the computational skills and making literacy to address such problems with IoT on their own. This lack of computational skills is augmented in IoT, as it represents a new paradigm of interaction between humans and computers (Dibitonto et al., 2018).

One approach to overcoming this lack of computational skills and making with IoT is to support operators in problem-solving through collaborative design activities in workshops. The support can be in the form of generative toolkits, which are a set of props designed to enable people (non-designers) to generate and express their ideas (Sanders and Stappers, 2014).

From a literature perspective, during the last few years, a foundation landscape of IoT toolkits has emerged to support participants with different approaches (Kurze et al., 2019). Furthermore, novel products in the market simplify the use of sensors and address, to some extent, the need for programming or electronic knowledge. However, IoT toolkits are in their infancy and there is currently a knowledge gap in ideation tools for IoT (Peters et al., 2020).

To address both this gap and this opportunity, in a previous case-study (Muñoz et al., 2020), we presented the Karakuri IoT card deck as a support tool for operators to ideate and conceptualise IoT solutions. This deck of cards was tested in four workshops in different manufacturing settings. Results indicated that operators were able to conceptually solve the problems they face on a daily basis using IoT. Based on the empirical material collected from the case-study, we conducted five different reflective sessions and studied Industry 4.0 and IoT support literature in order to answer two emerging research questions:

RQ1: How do IoT generative toolkits support operators in industrial settings?

$\mathrm{RQ} 2$ : What are the motivations for designing IoT generative toolkits for operators?

\section{THEORETICAL PERSPECTIVE}

To include people (non-designers, non-programmers) in the design process allows them to participate and to express themselves. This expressiveness can be supported with generative toolkits, which provide visual ways for people to make artifacts and express ideas that otherwise would be difficult to communicate verbally (Sanders and Stappers, 2014). When people engage in making, they visualise their thoughts in a tangible way and benefit, as designers do, from the creation of prototypes: people construct visible features that can be discussed, explained, interpreted, reflected and iterated (Sanders and Stappers, 2014). This participation and interaction with materials in the form of toolkits can be understood as a way to manipulate tangibles (e.g., cards) in a social context and space, where tangibles can be placed and rearranged to infer meaning and new ways of understanding (Tversky, 2011). Furthermore, tangibles as design tools can help in the "perception and understanding of design problems and solutions" (Dalsgaard, 2017). On one hand, the themes of tangible manipulation, spatial interaction, embodied facilitation and expressive representation of Hornecker and Buur's framework (2006) are helpful in analysing human interaction from a tangible perspective. On the other hand, Dalsgaard's instruments of inquiry framework (2017) can provide ways to better understand the role that design tools as instruments of inquiry play in design activities and how they can support the creation of new solutions.

The hypothesis relating to this inclusion and collaborative design is that it potentially leads to a world made from people's dreams (Sanders, 2000), proposing in this process that as people solve their own problems, they might also shape the landscape of a new world (Manzini, 2015). 


\section{METHOD}

Building on the tradition of creating tools and methods to involve and enable people in collaborative idea generation and making, we have studied previous research on IoT support. We didn't follow a systematic literature review, as it is quite difficult to map the variety of terms that designers employ to create design methods and tools, and the terminology is not consistent (Peters et al., 2020). Rather, the review began with "IoT toolkits", "IoT cards" and "IoT Workshop" and evolved based on references found in articles considered relevant for this study (up until the 26th of October 2020). For context, this review is complemented by previous research on operators and Industry 4.0.

In respect to the case-study, the method that we followed is design workshops (Hanington and Martin, 2019), in which the research team acted as facilitators to support operators in designing conceptual solutions with the Karakuri card deck.

Workshop attendees assumed diverse roles on the shop floor as, for example, technicians, logistic personnel, machinery and maintenance operators, and IT personnel (see workshop information on Table 1). Each of the four workshops lasted from two to two and a half hours and followed the same agenda and presentation. The first workshop was considered a pilot study, as the Karakuri IoT cards were presented for the first time and based on the findings, redesigned for the subsequent workshops: A, B and C (Muñoz et al., 2020). Each workshop started with a presentation by the researchers with instructions on how to use the Karakuri IoT card decks. Participants then presented problems they had previously identified in Stage 1 workshops and had 60 minutes to collaboratively ideate conceptual solutions. At the end, participants presented their results to the other participants and to the research team. The final 30 minutes were reserved for a reflective discussion with all participants and with the research team.

Table 1. Case-study workshops information.

\begin{tabular}{|l|c|c|c|c|}
\hline & Pilot & Workshop A & Workshop B & Workshop C \\
\hline No. Participants & 7 & 7 & 7 & 7 \\
\hline No. Groups & 2 & 3 & 3 & 2 \\
\hline
\end{tabular}

The research team took notes during the workshops and collected the resulting twenty-one conceptual solutions and storyboards made by participants. Workers took pictures of the corresponding companies. In addition to this material, informal discussions with managers from these manufacturing industries were considered for the analysis (see Figure 1). The analysis of this collected material was done in 5 different reflective sessions with different members of the research team and with follow-up discussions over the span of six months.

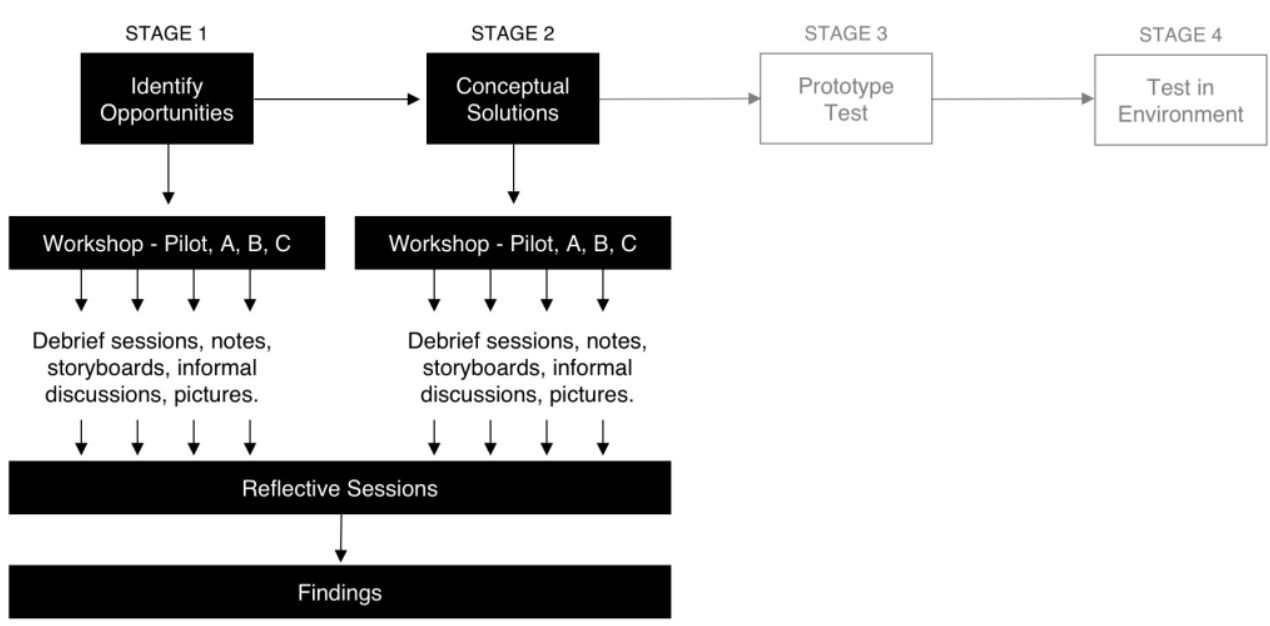

Figure 1. Material collected from stage 1 and 2 workshops for analysis.

\section{THE OPERATOR'S ROLE IN INDUSTRY 4.0}

The fourth industrial revolution is based on the German vision of Industry 4.0 (Kagermann et al., 2013), and relies on new technological enablers such as the IoT and Services, Cyber-Physical systems 
and Digital Twins, with the promise of sustaining a new smart manufacturing paradigm. The incorporation of these novel technologies into Industry 4.0 will have an impact on operators, as new means of human-machine interaction will emerge from the blending of digital and physical environments (Romero et al., 2020).

While these technologies are integrated into the manufacturing settings, it is expected that industrial workers will require new skills at work (Pinzone et al., 2017), as studies focus on planning how to teach the required skills in order to support innovation and competitiveness (Pinzone et al., 2016), and guarantee a socially sustainable manufacturing industry (Pinzone et al., 2020).

These technological influences on operators (and their consequences) have been debated over the last decade with two competing scenarios considering how the vision of Industry 4.0 will materialize in manufacturing practices. On one hand, the technocentric view is based on the hypothesis that technology will lead and control human work; on the other hand, the anthropocentric view implies that humans will be decision-makers supported by technology (Dworschak and Zaiser, 2014).

According to the anthropocentric perspective, there are different approaches that accommodate the expected influence of Industry 4.0. An example is the concept of Operator 4.0 presented by David et al. (2016) that focuses on the relationship between operators and machines and how operators can be empowered with new skills and technology. This concept considers a typology of eight different roles for operators based on how they can be supported with technologies (David et al., 2016). Examples of such roles include super-strength operators (e.g., exoskeletons), augmented operators (augmented reality) and healthy operators (wearable technology). In this regard, the concept of operator 4.0 relies as much on human skills and competences as on technology (Romero et al., 2020).

Taylor et al. (2020) take an alternate viewpoint, one in which the operator doesn't need enhanced abilities derived from new technological developments, e.g., super-strength. Instead, their goal is to foster the creativity of the operator in order to achieve higher levels of innovation and safety. This Operator 4.0 concept is known as the Maker 1.0., where operators have a more creative and intellectual role in Industry 4.0 than simply "assisting or monitoring non-discretionary work flow steps or processes". However, this raises the concern for "de-skilled work and human passivity" (Taylor et al., 2020). Following this maker interpretation of the Operator 4.0, it is possible to find visions of Industry 4.0 that are more inclusive and aimed not only at supporting operators with different experience and skills, but also empowering them to develop their skills (Kaasinen et al., 2020). In this regard, Kaasinen et al. (2020) present evidence that industrial workers seek more involvement in incorporating new developments within their contexts in the form of Operator 4.0 concepts:

"The workers would like to be more involved in the design of the workplace and manufacturing processes, and they thought that participation would decrease many problems that they currently face in their work." (Kaasinen et al., 2020)

\section{IOT SUPPORT AND THE ROLE OF OPERATORS}

In recent years, support tools in different forms have been presented for the facilitation of IoT ideation and making with different approaches, contexts and target participants. In this respect, there is a knowledge gap in ideation tools for IoT (Peters et al., 2020). It is relevant to address this gap because designing and ideating with IoT technologies presents a new interactive paradigm (Dibitonto et al., 2018) that requires a different approach than with other technologies. IoT presents a combination of digital and physical elements (Roeck et al., 2014) which increases the complexity of IoT solution development (Udoh and Kotonya, 2018).

From an analogue perspective, the 'IoT deck' (Hao et al., 2011) supports ideation for designers and considers twenty IoT aspects observed in literature; the 'Tiles' card toolkit supports non-experts in the ideation and invention of new connected products in workshops (Mora et al., 2017); the 'IoT Design kit' supports teams in the ideation process and acknowledges different starting points in the conceptualisation of IoT solutions (Roeck et al., 2019); the 'IoT design deck' supports teams in the User Experience (UX) aspects of co-designing IoT products (Dibitonto et al., 2018); the 'IoT Service Toolkit' is a board game that enables co-creation among domain experts (Brito and Houghton, n.d.); the 'Knowcards' (Aspiala and Deschamps-Sonsino, n.d.) support with IoT activities such as brainstorming; the Co-Creative Workshop format supports the development of IoT solutions from a citizen perspective (Kranenburg et al., 2014), with a corresponding toolkit that aims to create IoT solutions by supporting experts and endusers; the framework from Berger et al. (2019) helps to analyse co-design stories through IoT toolkits; 
the framework from Vitali et al. (2016) aims to analyse IoT dimensions from a product design perspective considering design, technology, market and user lenses; the 'MappingTheIoT Toolkit' supports the design of products with IoT (Ilaria and Venanzio, 2018); and the 'Un-Kit' provides a set of sensors and actuators without functionality or connectivity, meant to encourage engagement "in exploring, designing and generating personally meaningful IoT applications" (Ambe et al., 2019).

From a hardware perspective, the literature also provides examples on how to support ideation, conceptualisation and prototyping with IoT devices. For example, littleBits are a set of pre-assembled electronics that can be used as "sketching materials" (Bdeir and Ullrich, 2010); 'Loaded Dice' is a set of dice that include sensors and actuators aimed at supporting the early phases of co-design for connected products and has been tested in workshops with visually impaired and blind users (Lefeuvre et al., 2017); and the 'CodeMe' and 'ConnectUs' Toolkit aim to introduce different IoT notions to children (Lechelt et al., 2016). There are also available products in the market which aim to mask the complexity of IoT technologies (e.g, Sony MESH, Sam Labs).

These analogue and hardware methods both provide different ways to support users in different phases of the design process. However, it is difficult (even for the creators of the methods) to specifically locate where the methods belong in the design process (Kurze et al., 2019).

An alternate approach is to provide users with support tools that help them define and structure IoT ideas and concepts. For example, De Roeck et al. (2014) presented a study comparing two different notation systems for IoT to support designers: the tangible business process modelling (tBPM) and Lillidots. On one hand, the tBPM is a set of tangibles that participants can use to create an overview of the system in the form of a process model. On the other hand, Lillidot is a method that facilitates the creation of ideas by considering digital aspects in a structured way. However, unlike languages such as Unified Modeling Language (UML) or Object Modeling Language (OML) neither of these two notation tools are intended "to result in the description of a software system" (Roeck et al., 2014).

\section{THE CASE-STUDY}

The Karakuri IoT project includes four large and two small manufacturing companies that produce construction equipment, electronics, printed circuit boards and metal cutting machinery, among other products. Two research institutes and two university departments (design and improvement of production systems, information design) participate in the project. The team is composed of a senior researcher on Industrial Internet of Things (IIoT), a researcher on kaizen and lean production, and an interaction designer (PhD student).

The project is inspired by the Karakuri kaizen manufacturing movement. Originating in Japan, this movement aims to implement simple automation mechanisms through the use of natural energy (no external power source) with the end goal of creating improvements in the manufacturing process (Katayama et al., 2014). The project goal is to develop the Karakuri kaizen movement one step further by including IoT devices that are simple to use in these improvement creations. The aim is that operators can capitalize on improvement opportunities that require sensors and actuators, so they can propose IoT concepts which they can later prototype and test by themselves. In order to reach this goal, we conducted a pre-study (Yamamoto et al., 2018a) and continued with a research project to develop a bottom-up methodology (Figure 2) to support operators in ideation, conceptualization, prototyping and testing with IoT technologies (Yamamoto et al., 2018b).

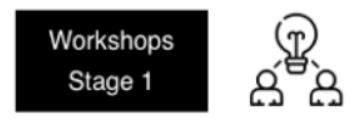

Participants are encouraged to brainstorm problems that they face on a daily basis and on improvement opportunities.

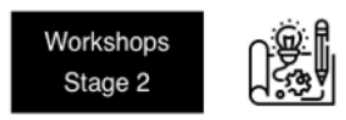

Participants use the Karakuri loT Deck as support for conceptualizing improvement solutions selected from Stage 1.

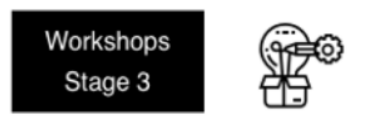

Using the Karakuri loT hardware and software modules, participants prototype their conceptual solutions presented in Stage 2.

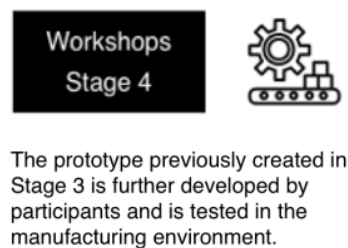

manufacturing environment.

Figure 2. Workshop stages of Karakuri loT methodology.

The Karakuri IoT card deck was designed to support Stage 2 workshops in order to assist operators in conceptualizing IoT solutions. The deck includes 32 cards that can be classified into four different categories: sense, notify, analyse and jokers (see Figure 3). Operators used this deck in four Stage 2 workshops to come up with conceptual solutions and storyboards to convey how they would capitalize 
on an improvement opportunity in their respective manufacturing settings. All of these solutions were considered possible IoT concepts when explained to the research team (Muñoz et al., 2020).
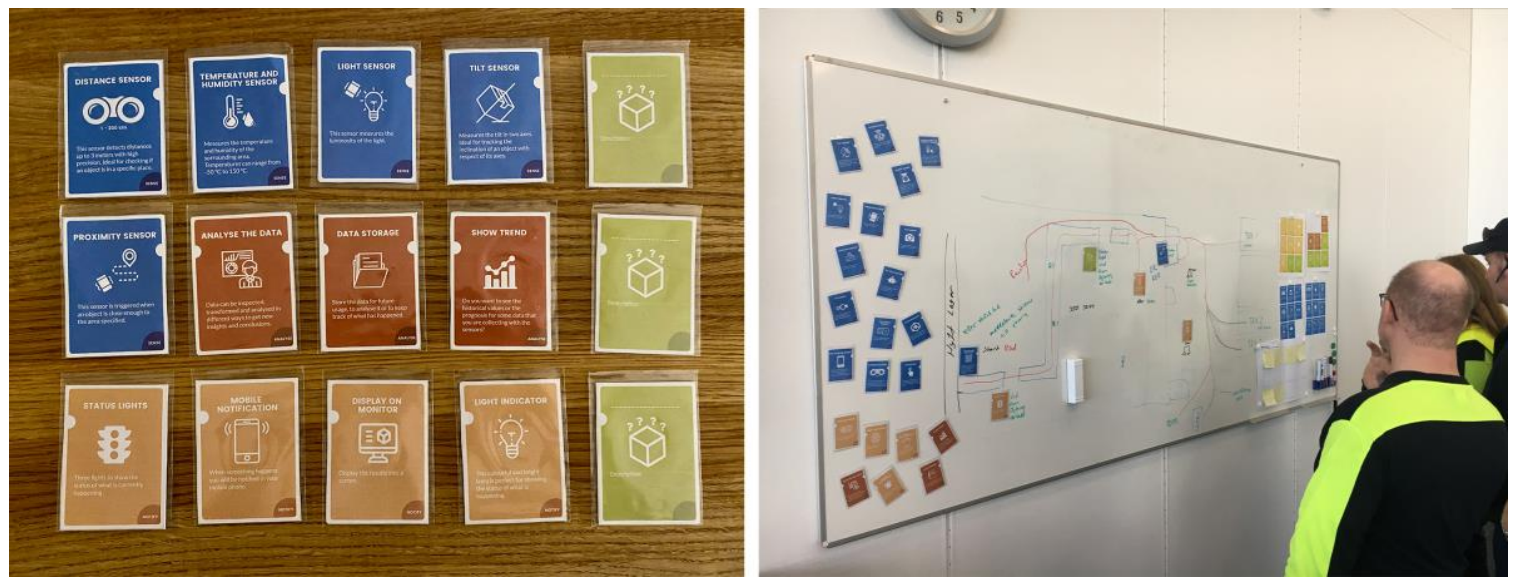

Figure 3. On the left, Karakuri loT cards (sensors, notifications, analysis opportunities and jokers). On the right, operators using the cards to create a conceptual solution.

During workshops, it was observed that operators could understand the different sensors, could discuss improvement opportunities with colleagues and could select and discard working combinations of sensors for their specific manufacturing settings. In order to engage with these concepts, participants discussed when and how often a problem occurs during a day, how and where they could attach specific sensors, what information they would expect to receive from the sensors, and their preferences and priorities for consuming that information. As a result, they were able to collaboratively brainstorm IoT conceptual ideas on how to improve their work environments. However, when analysing the resulting workshop data, we (the researchers) observed a limitation in the fact that some of the resulting concepts were difficult to interpret and ambiguous if not explained by operators. On one hand, this is because the resulting conceptual solutions, in the form of diagrams, only show a snapshot of how the solution works. There is implicit information in the diagrams which is hard to interpret unless present in the workshop discussions (e.g., arrows can depict movement of personnel or sequential actions). On the other hand, there is information that is never documented in the diagram despite being participant communication via commentaries or gestures, such as operator locations in the concepts or sensor and display placements.

Figure 4 shows an example of a simple conceptual solution, in which operators used a weight sensor to detect the weight of packaging boxes on a pallet. This concept works, in the sense that it depicts a problem (operators lacking packaging material) and a potential solution using a weight sensor to detect a scarcity of material (low weight) so an operator can place a new order and replenish it. It takes into account how the operator would like to consume the information (on a display, with the message "time to order new boxes") and that the operator will need to place the order to change the status lights for the material. However, the conceptual solution still leaves open unknowns such as: once triggered, how long will the status lights remain on? Where will the status lights be placed, near a computer, the packaging boxes station or elsewhere? In this respect, the concepts could be further documented and developed.

Regarding development, we assume that participants will have time to better understand the solution during the prototyping stage (stage 3 workshops). The topic of documentation arose during the reflective sessions and focused on how to encourage participants to embed more details into the conceptual solutions and how to better embrace participants' computational thinking. The aim was that the conceptual solutions, in the form of diagrams, could help participants in the transition towards software diagrams in the subsequent prototyping stage of Karakuri IoT. However, the main strengths identified during the reflective sessions were the high degree of participant engagement during the workshops and that the workshop sessions were perceived as fun (this was observed by researchers during the workshops and brought up by managers in informal discussions after the workshops). In this respect, one of the main take-aways was that technical details and computational thinking were less important than engaging operators in expressing their needs. As long as operators are interested and can propose improvement opportunities with IoT technologies, experts in the information and communication technology (ICT) field can always help them to refine or further develop their concepts. 
Our interpretation is that operators need support that enables them to conceptualise and prototype, but that the quality of the technological solutions relies on the identification of improvements (framing of the problem) and the expression of needs, rather than the technical qualities normally discussed in software development fields.

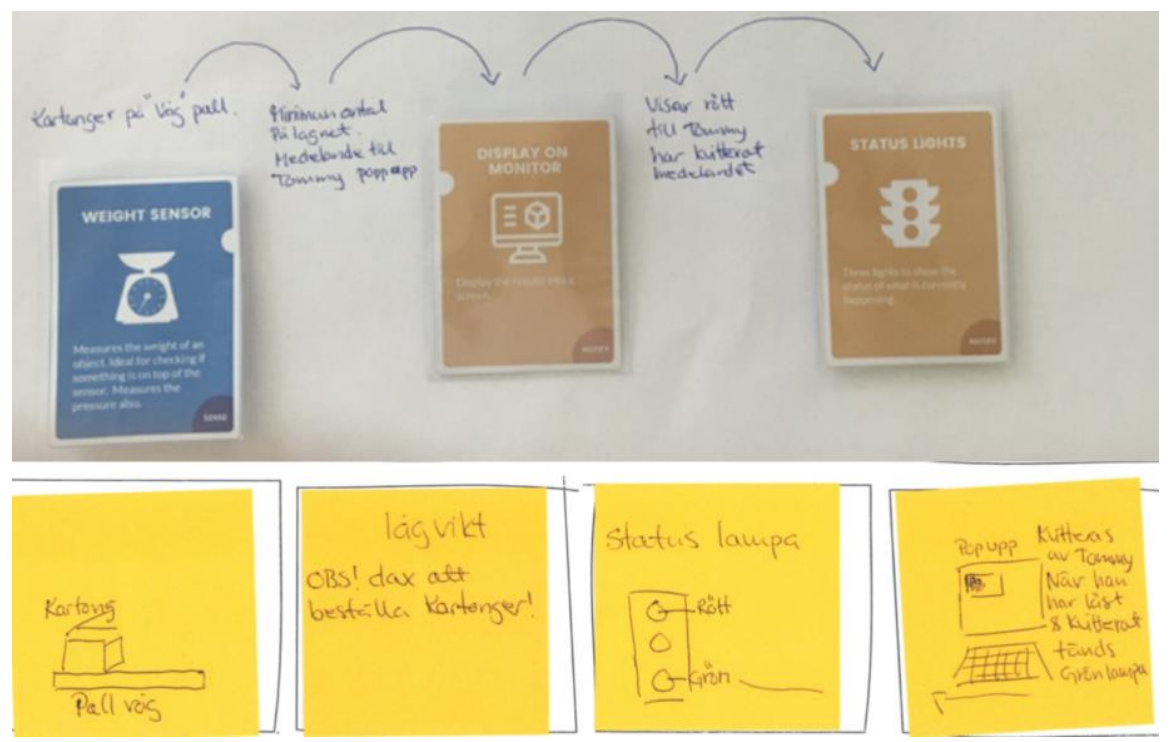

Figure 4. Above, conceptual solution: a weight sensor detects that more boxes are needed and notifies operators through a display and status lights. below, storyboard.

\section{DISCUSSION AND FUTURE WORK}

In the introduction we presented two research questions:

RQ1: how do IoT generative toolkits support operators in industrial settings?

RQ2: what are the motivations for designing IoT generative toolkits for operators?

Starting with RQ2, in the context of the human-centric literature view of Industry 4.0, we observed interest from industrial workers in being more involved; that recent conceptions of operator 4.0 depict factory workers as people with skills, competences and creativity; that one potential goal can be to unleash their creativity; and that due to the introduction of novel Industry 4.0 technologies, a reskilling is forthcoming. In light of these motivations found in the literature (and through our experience as practitioners and with the case-study), we see a viable gap and an opportunity to examine how collaborative design activities and support tools can help operators express their needs and exert their creativity at work. More specifically, we see an opportunity to study support for IoT, as IoT is already integrated on the shop floor and is one of the key enablers of Industry 4.0, where cyberphysical systems and digital twins are nurtured by the IoT infrastructure.

In relation to RQ1, in the case study we observed that operators are able to understand and collaboratively use sensors (at a conceptual level, using the Karakuri IoT card deck) to discuss potential ways to address previously identified challenges or opportunities that they see in their industrial environments. We have also seen evidence that in the material resulting from workshops (in the form of diagrams and storyboards) it is possible to see the problems addressed by operators and the resulting solutions, which also entails how operators intend to consume the information and to act on it. We also note that there are limitations: the resulting solutions aren't able to capture the whole solution, they leave some unknowns, and the drawings can be ambiguous. Based on this evidence, we see that there is great potential in designing support for operators and that more research in this area is needed.

Our hypothesis (and expectation) for future research on design support for operators, based on the presentation of the literature reviewed in this paper and the experiences from the case-study is that if operators become more familiar with IoT through collaborative design activities, then they will learn new skills related to the technological landscape that surrounds them in their daily activities; they can become more creative at work and likewise, demand more creative work; they can see technologyrelated opportunities and problems in their everyday work that would otherwise be invisible to them; they can develop acceptance of new IoT solutions and see their surrounding landscape not as a fixed environment imposed by technological experts and managers, but rather as flexible environments that 
can be changed based on their voice: they can be understood when they express their needs, concerns and dreams for possible industrial environments. In doing this, they can help create a more humanistic, creative and socially sustainable environment for themselves.

In regard to previous research on IoT support, we have seen a wide range of ways in which IoT support can help people (non-designers, non-programmers): we have seen evidence that analogue support without hardware (e.g., in the form of card decks) can enable collaborative idea generation and conceptualisation; that IoT hardware support simplifies and exemplifies the use of IoT, with goals such as teaching notions of IoT to people unfamiliar with this technology and to allow people to use IoT hardware as a material in the early stages of design and in prototyping. Furthermore, we have also seen IoT support in terms of notation, where IoT aspects can be considered in a more structured way without reaching complex levels of software systems.

The literature revealed that there is not a strong focus on the analysis of the resulting artifacts made by participants. In (Sanders, 2000) we see a viable direction for this type of analysis, as the author argues that generative toolkits present a new language that is both visual and verbal but suggests that it is mainly visual.

Looking forward, we see an opportunity to look into how the visual field can contribute to the analysis of participant results, and in light of visual theories, more rigorously analyse the conceptual solutions presented by participants. We see an opportunity to address the resulting artifacts made by participants as an expression of their needs that can be used as a medium to communicate with domain experts in ICT. In this respect, the resulting artifacts (expression of participant needs) would be a bridge to ICT experts that can ideally help interpret those needs as implementations and integrations into the shop floor. Hence, we need to support participants in not only expressing their needs through artifacts, but also to emphasize the potential communicative aspects of those artifacts so the needs are understandable to external people who might not be involved in the workshops, or so that participants can rely on specific features of the artifacts (supported and emphasized during workshops) to express their needs. Lastly, as our main intention is to facilitate participants in designing by themselves (with support tools, with facilitation), we see the need to support them in being critical and reflecting on the potential consequences of their inventions and improvements. E.g., will there be safety hazards if their IoT solution malfunctions? Will they design an IoT prototype that will unintentionally track their personal data or other sensitive data?

\section{CONCLUSION}

This paper presented a case-study composed of four different manufacturing settings supporting operators in the conceptualisation of manufacturing improvements using IoT technologies. The collected empirical material was analysed over five different reflective sessions and discussed in light of previous research on IoT support and Industry 4.0. Results provide evidence that operators, with IoT support, can unleash their creativity and propose conceptual IoT solutions. The approach was to overcome a lack of computational skills and making with IoT by supporting operators in problem-solving and collaborative design activities during workshops. It has been observed that the quality of their conceptual solutions builds on how they identify and frame problems, and how they express their contextual needs rather than the technical aspects and computational qualities normally addressed in computer science. In this respect, the results suggest that technological expressiveness can be a skill to consider for the shop floor transition to new technological paradigms such as Industry 4.0. This skill can be supported with generative toolkits and collaborative design activities. If achieved, technological expressiveness can enable operators to communicate technological needs and capitalize on technological improvements. This case-study shows that such expressiveness presents generic implications for the future, and can contribute to more creative, effective and socially sustainable industry.

\section{ACKNOWLEDGMENTS}

This work is funded by the Vinnova Swedish agency.

\section{REFERENCES}

Ambe, A.H., Brereton, M., Soro, A., Chai, M.Z., Buys, L. and Roe, P. (2019), “Older People Inventing Their Personal Internet of Things with the IoT Un-Kit Experience", Proceedings of the 2019 CHI Conference on 
Human Factors in Computing Systems, ACM, New York, NY, USA, pp. 1-15. https://doi.org/10.1145/3290605.3300552

Aspiala, T. and Deschamps-Sonsino, A. (n.d.). "Know Cards: Learn. Play. Collect.”, available at: https://knowcards.myshopify.com/ (accessed 23 September 2020).

Bdeir, A. and Ullrich, T. (2010), "Electronics as Material: LittleBits", Proceedings of the Fifth International Conference on Tangible, Embedded, and Embodied Interaction, ACM, New York, NY, USA, pp. 341-344. https://doi.org/10.1145/1517664.1517743

Berger, A., Ambe, A.H., Soro, A., Roeck, D.D. and Brereton, M. (2019), “The Stories People Tell About The Home Through IoT Toolkits", Proceedings of the 2019 on Designing Interactive Systems Conference, ACM, New York, NY, USA, pp. 7-19. https://doi.org/10.1145/3322276.3322308

Brito, R. and Houghton, P. (n.d.). "IoT Service Kit", available at: https://iotservicekit.com/ (accessed 21 September 2020).

Dalsgaard, P. (2017), "Instruments of Inquiry: Understanding the Nature and Role of Tools in Design", Nternational Journal of Design. Available: http://www.ijdesign.org/index.php/IJDesign/article/view/2275

David, R., Stahre, J., Wuest, T., Noran, O.S., Bernus, P., Berglund, A. and Gorecky, D. (2016), “Towards an operator 4.0 typology: a human-centric perspective on the fourth industrial revolution technologies".

Dibitonto, M., Tazzi, F., Leszczynska, K. and Medaglia, C.M. (2018), "The IoT Design Deck: A Tool for the Co-design of Connected Products", in Ahram T., Falcão C (Eds.), Springer International Publishing, Cham, pp. 217-227. https://dx.doi.org/10.1007/978-3-319-60492-3_21

Dworschak, B. and Zaiser, H. (2014), "Competences for Cyber-physical Systems in Manufacturing - First Findings and Scenarios”, Procedia CIRP, Vol. 25, pp. 345-350. https://doi.org/10.1016/j.procir.2014.10.048

Gorecky, D., Schmitt, M., Loskyll, M. and Zühlke, D. (2014), "Human-machine-interaction in the industry 4.0 era", 12th IEEE International Conference on Industrial Informatics (INDIN), Porto Alegre, 2014, pp. 289294. https://doi.org/10.1109/INDIN.2014.6945523

Hanington, B. and Martin, B. (2019), Universal Methods of Design Expanded and Revised: 125 Ways to Research Complex Problems, Develop Innovative Ideas, and Design Effective Solutions, Rockport Publishers Inc.

Hao, C.Y., Huei, L.R. and Dar, C.C. (2011), "IoT Deck: a digital card-based ideation game to inspire Internet of Things Design", Proceedings of IASDR2011, the 4th World Conference on Design Research.

Hornecker, E. and Buur, J. (2006), "Getting a Grip on Tangible Interaction: A Framework on Physical Space and Social Interaction", Proceedings of the SIGCHI Conference on Human Factors in Computing Systems, ACM, New York, NY, USA, pp. 437-446. https://doi.org/10.1145/1124772.1124838

Ilaria, V. and Venanzio, A. (2018), "Developing a Design Toolkit for the Internet of Things", Proceedings of DRS 2018 International Conference: Catalyst, Design Research Society, available at: https://doi.org/10.21606/drs.2018.447

Kaasinen, E., Schmalfuß, F., Özturk, C., Aromaa, S., Boubekeur, M., Heilala, J., Heikkilä, P., et al. (2020), "Empowering and engaging industrial workers with Operator 4.0 solutions", Computers \& Industrial Engineering, Vol. 139, p. 105678. https://doi.org/10.1016/j.cie.2019.01.052

Kagermann, H., Wahlster, W., Helbig, J. (2013), "Recommendations for implementing the strategic initiative INDUSTRIE 4.0”. Final report of the Industrie 4.0 Working Group.

Katayama, H., Sawa, K., Hwang, R., Ishiwatari, N. and Hayashi, N. (2014), “Analysis and classification of Karakuri technologies for reinforcement of their visibility, improvement and transferability: An attempt for enhancing lean management", Proceedings of PICMET '14 Conference; Infrastructure and Service Integration, Kanazawa, pp. 1895-1906. Electronic ISBN:978-1-890843-29-8

Kranenburg, R., Stembert, N., Moreno, M.V., Skarmeta, A.F., López, C., Elicegui, I. and Sánchez, L. (2014), "Co-creation as the Key to a Public, Thriving, Inclusive and Meaningful EU IoT", in Hervás, R., Lee, S., Nugent, C. and Bravo J. (Eds.), Springer, Cham, pp. 396. https://doi.org/10.1007/978-3-319-13102-3_65

Kurze, A., Totzauer, S., Deschamps-Sonsino, A. and Berger, A. (2019), “A Collaborative Landscaping Exercise of IoT Design Methods", Proceedings of the 31st Australian Conference on Human-Computer-Interaction, ACM, New York, NY, USA, pp. 307-311. https://doi.org/10.1145/3369457.3369484

Lechelt, Z., Rogers, Y., Marquardt, N. and Shum, V. (2016), "ConnectUs: A New Toolkit for Teaching about the Internet of Things", Proceedings of the 2016 CHI Extended Abstracts on Human Factors in Computing Systems, ACM, New York, NY, USA, pp. 3711-3714. https://doi.org/10.1145/2851581.2890241

Lefeuvre, K., Totzauer, S., Bischof, A., Storz, M., Kurze, A. and Berger, A. (2017), "Loaded Dice: How to cheat your way to creativity", RTD Conference. https://doi.org/10.6084/m9.figshare.4746976.v1.

Manzini, E. (2015), Design, When Everybody Designs, The MIT Press. ISBN: 9780262028608.

Mora, S., Gianni, F. and Divitini, M. (2017), "Tiles: A Card-Based Ideation Toolkit for the Internet of Things", Proceedings of the 2017 Conference on Designing Interactive Systems, ACM, New York, NY, USA, pp. 587-598. https://doi.org/10.1145/3064663.3064699

Muñoz, Á.A., Florin, U., Eriksson, Y., Yamamoto, Y. and Sandström, K. (2020), “The Karakuri Card Deck: co-designing industrial IoT Conceptual Solutions", Cambridge Core, Vol. 1, pp. 807-816. https://doi.org/10.1017/dsd.2020.127 
Peters, D., Loke, L. and Ahmadpour, N. (2020), "Toolkits, cards and games - a review of analogue tools for collaborative ideation", CoDesign, pp. 1-25. https://doi.org/10.1080/15710882.2020.1715444

Pinzone M., Albè F., Orlandelli D., Barletta I., Berlin C., Johansson B. and Taisch M. (2020), “A framework for operative and social sustainability functionalities in Human-Centric Cyber-Physical Production Systems", Computers \& Industrial Engineering, Vol. 139, p. 105132. https://doi.org/10.1016/j.cie.2018.03.028

Pinzone, M., Fantini, P., Fiasché, M. and Taisch, M. (2016), “A Multi-horizon, Multi-objective Training Planner: Building the Skills for Manufacturing”, in: Bassis S., Esposito A., Morabito F. and Pasero E. (Eds.). Springer, Cham, pp. 517-526. https://doi.org/10.1007/978-3-319-33747-0_51

Pinzone, M., Fantini, P., Perini, S., Garavaglia, S., Taisch, M. and Miragliotta, G. (2017), "Jobs and Skills in Industry 4.0: An Exploratory Research", in Lödding H., Riedel R., Thoben KD., von Cieminski G and Kiritsis D. (Eds.), Springer, Cham, pp. 282-288. https://doi.org/10.1007/978-3-319-66923-6_33

Roeck, D.D., Stappers, P.J. and Standaert, A. (2014), “Gearing up! A Designer-Focused Evaluation of Ideation Tools for Connected Products", Proceedings of the 8th Nordic Conference on HCI: Fun, Fast, Foundational, ACM, New York, NY, USA, pp. 521-530. https://doi.org/10.1145/2639189.2639204

Roeck, D.D., Tanghe, J., Jacoby, A., Moons, I. and Slegers, K. (2019), "Ideas of Things: The IOT Design Kit", Companion Publication of the 2019 on Designing Interactive Systems Conference 2019 Companion, ACM, New York, NY, USA, pp. 159-163. https://doi.org/10.1145/3301019.3323888

Romero, D., Stahre, J. and Taisch, M. (2020), "The Operator 4.0: Towards socially sustainable factories of the future”, Comput. Ind. Eng., Vol. 139, p. 106128. https://doi.org/10.1016/j.cie.2019.106128

Sanders, E.B.-N. (2000), "Generative Tools for Co-designing”, in Scrivener S.A.R., Ball L.J. and Woodcock A. (Eds.), Springer, London, pp. 3-12. https://doi.org/10.1007/978-1-4471-0779-8_1

Sanders, E.B.-N. and Stappers, P.J. (2014), "Probes, toolkits and prototypes: three approaches to making in codesigning”, CoDesign, Vol. 10 No. 1, pp. 5-14. https://doi.org/10.1080/15710882.2014.888183

Taylor, M.P., Boxall, P., Chen, J.J.J., Xu, X., Liew, A. and Adeniji, A. (2020), “Operator 4.0 or Maker 1.0? Exploring the implications of Industrie 4.0 for innovation, safety and quality of work in small economies and enterprises", Computers \& Industrial Engineering, Vol. 139, p. 105486. https://doi.org/10.1016/j.cie.2018.10.047

Tversky, B. (2011), "Visualizing Thought”, Topics in Cognitive Science, Vol. 3 No. 3, pp. 499-535. https://doi.org/10.1111/j.1756-8765.2010.01113.x

Udoh, I.S. and Kotonya, G. (2018), "Developing IoT applications: challenges and frameworks", IET CyberPhysical Systems: Theory \& Applications, Vol. 3 No. 2, pp. 65-72. https://doi.org/10.1049/ietcps.2017.0068

Vitali, I., Rognoli, V. and Arquilla, V. (2016), "Mapping the IoT: Co-Design, Test and Refine a Design Framework for IoT Products", Proceedings of the 9th Nordic Conference on Human-Computer Interaction, ACM, New York, NY, USA. https://doi.org/10.1145/2971485.2987681.

Wichmann, R.L., Eisenbart, B. and Gericke, K. (2019), “The Direction of Industry: A Literature Review on Industry 4.0", Cambridge Core, Vol. 1 No. 1, pp. 2129-2138. https://doi.org/10.1017/dsi.2019.219

Yamamoto, Y., Sandström, K. and Munoz, A.A. (2018a), "Karakuri iot - the concept and the result of prestudy", DiVA, Vol. 8, pp. 311-316. https://doi.org/10.3233/978-1-61499-902-7-311

Yamamoto, Y., Sandström, K. and Munoz, A.A. (2018b), "Development of methods that support exploration of simple and low-cost IoT-aided improvement solutions at manufacturing plants", DiVA. 